\title{
THE EFFECT OF THE POP-UP BOOK AKU DAN GIGIKU ON PULSE RATE IN CHILDREN AGED 4-6 YEARS
}

\author{
MEUTIA D CITRAWUNI ${ }^{1}$, MARGARETHA SUHARSINI ${ }^{2 *}$, EVA FAUZIAH ${ }^{2}$, KUSUMA P ADRIANI ${ }^{1}$ \\ ${ }^{1}$ Department of Pediatric Dentistry Residency Program, Faculty of Dentistry, Universitas Indonesia, Jakarta, Indonesia. ${ }^{2}$ Department of \\ Pediatric Dentistry, Faculty of Dentistry, Universitas Indonesia, Jakarta, Indonesia. Email: Margarethasuharsini@gmail.com
}

Received: 16 September 2017, Revised and Accepted: 3 October 2017

\section{ABSTRACT}

Objective: Anxiety is regarded as a major problem in children undergoing dental treatment. One of the physiological responses to anxiety is an increased pulse rate. Young children respond aggressively to anxiety and are in need of psychological intervention. Pop-up books can be used as an instrument to improve their interest and to help them understand the substance of dental health education.

The objective of this study was to utilize pulse rate measurements to investigate the intervention of a pop-up book in reducing anxiety. A total of 78 children aged 4-6 years were divided into two groups: An intervention group with the pop-up book Aku dan Gigiku and a control group without intervention. The pulse rates of both groups were measured. This study comprised an experimental clinical research design. The independent $t$-test was used to measure comparisons of decreased pulse rate between the two groups.

Result: The result showed that there was a statistically significant difference in decreased pulse rate with and without the intervention of the pop-up book Aku dan Gigiku. Pop-up books are often used as an educational medium for children because they present interesting illustrations and are easy to understand.

Conclusion: As a medium of dental health education, pop-up books can contribute significantly to reducing anxiety in children.

Keywords: Pulse rate, Children, Oral health education.

(c) 2017 The Authors. Published by Innovare Academic Sciences Pvt Ltd. This is an open access article under the CC BY license (http://creativecommons. org/licenses/by/4. 0/) DOI: http://dx.doi.org/10.22159/ijap.2017.v9s2.36

\section{INTRODUCTION}

Dental anxiety is a major factor in dental practice. In pediatric dental care, children may become uncooperative due to anxiety or stress related to treatment, making the treatment difficult to perform [1]. The child's perception of the dental environment is also a significant factor causing the anxiety [2]. Several studies have suggested that dental procedures might induce patient stress and thus affect the cardiovascular system [3]. According to the National Institutes of Health, a rapid pulse or arrhythmia may occur during episodes of anxiety [4]. Normally, in children, the pulse is frequently found to increase in the dental environment due to anxiety [5]. If patients are not managed appropriately, it is quite possible to establish what has been referred to as a "vicious cycle of dental fear."

Patients avoid making dental visits due to their fear, which results in a worsening of problems, requiring more intensive and potentially traumatic treatment, which then reinforces or exacerbates the fear, which leads to continued avoidance [6]. Thus, evaluating the psychophysiological reactions involve pulse rate can enable professionals to identify its occurrence and search for solutions to reduce its negative effects $[5,7]$.

A variety of behavioral interventions designed to reduce distress in children during intrusive dental treatment have been investigated [5]. Young children respond more aggressively to anxiety and are therefore in need of psychological intervention [8]. Pop-up books are often used as a medium of education for children because they present interesting illustrations and are easy to understand [9]. Pop-up books are a form of three-dimensional interactive literature that allows the child to become involved with the story. It has grown to become a genre that delights and educates children of all ages. These interventions have sought to decrease anxious and disruptive behavior and to teach children to be more adaptive [8].

Good communication skills and establishing rapport with the patient are critical in these circumstances [10]. The objective of this study was to assess the effect of the pop-up book Aku dan Gigiku to changes in the pulse rate in children aged $4-6$ years.

\section{METHODS}

The study subjects comprised 78 children from five kindergartens, between the ages of 4 and 6 years. They were evaluated to ascertain compliance with the following inclusion criteria: Absence of dental treatment; absence of chronic illness; absence of pain of dental origin; and no use of medication. We excluded subjects with special needs. Parents were informed of all the details of the investigation, and their written consent was required for their child's participation.

On children arrived at school, they were asked to take a seat in the classroom, where the first pulse rate measurements were recorded. An automatic wrist pulse rate monitor was used for the measurement. To use this monitor, the cuff is placed over the child's wrist and wrapped securely around for taking accurate measurements while the palm is facing upward. The cuff should be at the same level as the heart. The cuff will start to inflate automatically after pressing the start button. All the symbols appear on display.

Subsequently, half of the children were randomly assigned to the control group, which received no intervention before the oral prophylaxis procedure. The other half received the intervention of the pop-up book Aku dan Gigiku before the dental procedure. Thereafter, the second 
pulse rate measurements were performed immediately before the oral prophylaxis procedure.

This is an experimental clinical research design. The independent $t$-test was used to compare the changes in the pulse rate between the intervention and control groups. $\mathrm{p}<0.05$ was considered a statistically significant difference (Table 1).

\section{RESULTS}

To assess the effect of the pop-up book Aku dan Gigiku in reducing dental anxiety in early-aged children, changes in the pulse rate in the two groups were recorded. Before each analysis, the test of normality was applied to evaluate the data. In the statistical analysis, mean values and standard deviations were calculated for the number of changes in the pulse rate between the intervention and control groups.

The independent $t$-test was used to assess significant differences in the comparisons of the changes in pulse rate between the two groups. Statistical comparisons of the number of changes in the pulse rate indicated significant differences between the intervention groups with the pop-up book Aku dan Gigiku and the control group $\mathrm{p}=0.001$ $(\mathrm{p}<0.05)$.

\section{DISCUSSION}

Physiological responses to stress and anxiety result from interactions between the environment and the information processed by the central nervous system [7]. Several studies have suggested that dental procedures might induce patient stress and thus affect the cardiovascular system [3]. In normal children, the pulse is frequently found to increase in the dental environment due to anxiety [5]. Many treatments, which have been found to be effective in decreasing anxious and disruptive behavior, consist of a package of interventions [8].

The present study provides information about the effects of an intervention using the pop-up book Aku dan Gigiku to check the pulse rate in children aged 4-6 years who are undergoing dental treatment. The statistical analysis revealed significant differences in changes in pulse rate between the control groups, with no intervention, and the intervention group on being read the pop-up book Aku dan Gigiku before the oral prophylaxis procedure $(\mathrm{p}<0.05)$.

Previous studies showed no significant differences in changes in pulse rate before and after the dental procedure [7]. The study by Rodrigues Gomes et al. differed from the present study, in that, the latter utilizes the intervention of the pop-up book Aku dan Gigiku, which was given to each child of the intervention group before the dental procedure.

Pop-up books are a form of interactive literature that is often used as a medium of education for children because they present interesting illustrations and are easy to understand [9]. These interventions have sought to decrease anxious and disruptive behavior as well as to teach children to be more adaptive [8].

Our result suggests that the intervention of the pop-up book Aku dan Gigiku was an appropriate strategy in reducing children anxiety before
Table 1: Changes in pulse rate between the two groups

\begin{tabular}{llll}
\hline Group & $\mathbf{n}$ & Mean \pm SD $(\mathbf{b p m})$ & $\mathbf{p}$ \\
\hline Intervention group & 39 & $-12.8 \pm 4.8$ & 0.001 \\
Control group & 39 & $9.4 \pm 5.3$ & \\
\hline
\end{tabular}

SD: Standard deviation

dental procedures. Thus, the pop-up book Aku dan Gigiku is effective at reducing anxiety in young children.

\section{CONCLUSION}

The pulse rate measurements recorded in this study lead us to conclude that as a medium of dental health education, the pop-up book Aku dan Gigiku appears to be an effective method of reducing anxiety in young children before undergoing dental procedures. The pulse rate increases in response to a psychosocial stress paradigm. The sight of the dental procedure represents a significant source of stress among children aged 4-6 years. This finding is important in the behavioral management of young children who experience anxiety while undergoing dental procedures. Further, research is required to determine whether this finding holds true in special needs children of different age groups.

\section{ACKNOWLEDGMENT}

This article was fully supported and financed by PITTA grant Universitas Indonesia.

The publication of this manuscript is supported by Universitas Indonesia.

\section{REFERENCES}

1. Kato M, Kitamura T, Yanagida F, Yasui S, Takeyasu M, Daito M. Changes in amount of psychological palmar sweating in children at a dental office. Pediatr Dent J 2011;21:44-8.

2. Umamaheshwari N, Asokan S, Kumaran TS. Child friendly colors in a pediatric dental practice. J Indian Soc Pedod Prev Dent 2013;31:225-8

3. Kliegman R, Stanton B, Geme JS, Schor N. Nelson Textbook of Pediatrics. $19^{\text {th }}$ ed. Philadelphia, PA: Elsevier Saunders; 2011.

4. Wilson R. Taking Control of Anxiety Attacks. Don't Panic. $3^{\text {rd }}$ ed. North Carolina: Harper Perennial; 2009.

5. Appukuttan DP. Strategies to manage patients with dental anxiety and dental phobia: Literature review. Clin Cosmet Investig Dent 2016;8:35-50.

6. Australian Research Centre for Population Oral Health. Dental Fear and Anxiety: Information for Dental Practitioners. Colgate Dental Education Programs; 2016. Special Topic No. 11.

7. Rodrigues Gomes SS, Barretobezerra AC, Maia Prado AC. Salivary biomarkers, vital signs and behaviour of pre-school children during their first dental visit. Eur J Paediatr Dent 2013;14:279-83.

8. American Academy of Pediatric Dentistry. Guideline on behavior guidance for the pediatric dental patient. Pediatr Dent 2011;36:179-91.

9. Van Dyk S. Paper Engineering: Fold, Pull, Pop \& Turn. Washington DC: Smithsonian Institution Libraries; 2010.

10. Soeparmin. Pedodontic Treatment Triangle Berperan dalam Proses Keberhasilan Perawatan Gigi Anak. Interdental 2011;8:37-41. 